\title{
Pashto Language
}

National Cancer Institute

\section{Source}

National Cancer Institute. Pashto Language. NCI Thesaurus. Code C154081.

An Indo-European language spoken by the Pashtun people of Afghanistan and Pakistan. 